\title{
Selective Reinnervation of Intercostal Muscles Transplanted from Different Segmental Levels to a Common Site ${ }^{1}$
}

\author{
DONALD J. WIGSTON ${ }^{2}$ AND JOSHUA R. SANES ${ }^{3}$ \\ Department of Physiology and Biophysics, Washington University School of Medicine, St. Louis, Missouri 63110
}

\begin{abstract}
We transplanted external intercostal muscles from one of several thoracic $(T)$ levels to the neck of adult rats. The cervical sympathetic trunk, which innervates the superior cervical ganglion, was cut, and its proximal end was apposed to the muscle. Preganglionic axons in the trunk reinnervated muscle fibers in the transplants. We determined the segmental origin of synaptic inputs to transplanted muscles by recording intracellularly from muscle fibers while stimulating individual ventral roots which supply axons to the trunk. In one series of experiments, T2 or T8 muscles were transplanted from the thorax to the neck of the same rat. While T2 and T8 muscles were reinnervated to a similar extent, they differed in the segmental origin of the innervation they received: T2 muscles received more inputs from rostral segments (T1 and T2) than did T8 muscles, and T8 muscles received more inputs from caudal segments (T4 to T6) than did T2 muscles. This difference between reinnervation of T2 and T8 muscles was detected both 2 to 4 weeks and 10 to 14 weeks after surgery. In a separate series, using rats of an inbred strain, T3, T4, or T5 muscles were transplanted from one rat to a separate host. Again, the average segmental origin of inputs to transplants from different levels differed systematically: it was most rostral to T3 muscles, intermediate to T4 muscles, and most caudal to T5 muscles. Finally, T3 and T5 muscles were soaked in a myotoxin, Marcaine, before reimplantation. This treatment kills muscle fibers but not myoblastic satellite cells; therefore, muscle fibers were replaced by regeneration. Marcaine-treated T3 and T5 muscles were successfully reinnervated but did not differ significantly in the segmental origin of their inputs. Our results show that adult mammalian muscles can be selectively reinnervated, and they raise the possibility that the selectivity is based on some positional quality that matches axons and muscles from corresponding segments. However, while dif-
\end{abstract}

Received July 9, 1984;

Accepted October 1, 1984

\footnotetext{
${ }^{1}$ We thank D. Purves for advice and support, J. Cheney, D. Dill, and S. Eads for assistance, V. Friedman for illustrations, and A. Chiu, J. Covault, and $\mathrm{J}$. Lichtman for helptul comments. This work was supported by grants from the Muscular Dystrophy Association and the National Institutes of Health. $\mathrm{J}$. S. is an Established Investigator of the American Heart Association, and D. W. received a postdoctoral fellowship from the Muscular Dystrophy Association. A preliminary report of this work has appeared (Wigston and Sanes, 1983).

${ }^{2}$ Present address: Department of Physiology, Emory University School of Medicine, Atlanta, GA 30322.

${ }^{3}$ To whom correspondence should be addressed.
}

ferences among muscles survive denervation and transplantation, their expression or accessibility may change during regeneration.

Vertebrate skeletal muscles that arise from segmentally arranged somites are generally innervated by neurons in matching levels of the spinal cord (Corliss, 1976; Brodal, 1981; Carpenter and Sutin, 1983). While this pattern of innervation presumably arises in large part from spatial relationships between growing axons and muscles in the embryo, it is also possible that neurons and targets from corresponding levels have a special affinity for each other that promotes appropriate connectivity. We have therefore designed experiments to test whether neurons from different segments of the spinal cord can distinguish among (or be distinguished by) muscles from different segmental levels.

Our approach was to study the reinnervation of adult rat muscles transplanted from one of several segmental levels to a common site. The muscles we used were the external intercostals. These muscles, which connect pairs of adjacent ribs, form a set of 12 homologous muscles in the thorax. Each intercostal muscle develops from a single somite and is innervated by motor neurons that lie in the corresponding segment of the spinal cord and send axons through a single ventral root (Chevallier, 1979; Larnicol et al., 1982; Smith and Hollyday, 1983). The axons we used were the sympathetic proganglionics of the cervical sympathetic trunk, which normally innervate the superior cervical ganglion. We chose this nerve for two reasons. First, the cervical trunk contains axons that arise from neurons in 6 to 7 contiguous thoracic spinal cord segments. Axons from individual segments can be stimulated separately via the appropriate ventral root (Langley, 1892; Rubin and Purves, 1980). Second, axons of the cervical trunk are capable of selective synapse formation in the adult: axons from different spinal levels preferentially reinnervate different populations of neurons in the superior cervical ganglion (Langley, 1895, 1897; Guth and Bernstein, 1961; Njå and Purves, 1977b). Furthermore, in experiments that led to the work reported here, Purves et al. (1981) found that sympathetic ganglia transplanted to the bed of the excised superior cervical ganglion from a more caudal level are reinnervated by an overlapping but more caudally derived subset of axons than are reimplanted superior cervical ganglia.

Because sympathetic preganglionic axons can make functional synapses on skeletal muscle fibers (Langley and Anderson, 1904), we were able to ask whether intercostal muscles are selectively reinnervated by segmental subsets of preganglionic axons. We transplanted strips of external intercostal muscle from two different thoracic levels to the neck and assessed their reinnen ation by axons of the cervical trunk. We found that transplanted rostral muscles were reinnervated by axons from the more rostral segment than were transplanted caudal muscles (Wigston and Sanes, 1982). Here, we consider these results in greater detail, and extend them by studying muscles transplanted from a different set of segments as 


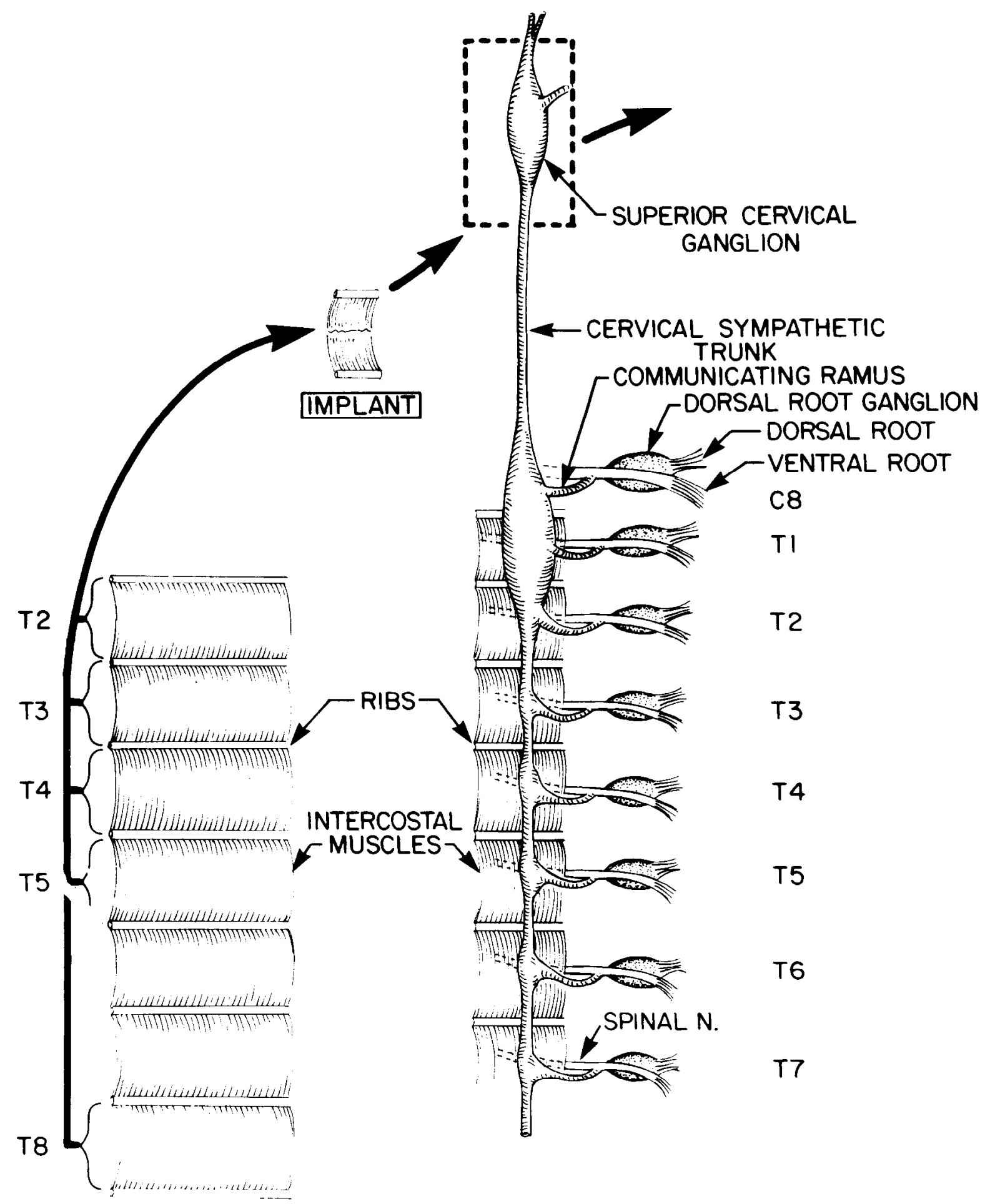

Figure 1. Diagram of the preparation used to compare reinnervation of muscles from different segmental levels. A strip of external intercostal muscle was transplanted from the 2nd, 3rd, 4th, 5th, or 8 th thoracic (T2, 3, 4, 5, or 8) interspace to the neck of an adult rat. The supcrior cervical ganglion was removed, and the cut end of the cervical sympathetic trunk was attached to the implant. Two to 14 weeks later, the muscle, cervical trunk, communicating rami, and ventral roots C8-T7 were dissected in continuity, and individual roots were stimulated to assess the segmental origin of inputs to the transplanted muscle. Drawing is nol lo scále.

well as muscles that were induced to degenerate and regenerate before being reinnervated.

\section{Materials and Methods}

Surgery. Pieces of external intercostal muscle were transplanted from the thorax to the neck and innervated by the cervical sympathetic trunk (Fig. 1). in one series of experiments, muscles were transplanted from the thorax to the ncck of the same rat. In a second series, muscles obtained from one rat were transplanted to the neck of another.

For autogeneic transplantation, a 150 - to $200-\mathrm{gm}$ male rat (SpragueDawley, obtained from Eldridge, St. Louis, MO) was anesthetized with chloral hydrate $(350 \mathrm{mg} / \mathrm{kg}$, i.p.), and an incision was made on the left side of its thorax. A 2- to 3-mm piece of either the T2 (with second and third ribs attached) or the T8 (with eighth and ninth ribs attached) intercostal muscle was removed and transferred to sterile saline (Liley, 1956). Each intercostal 

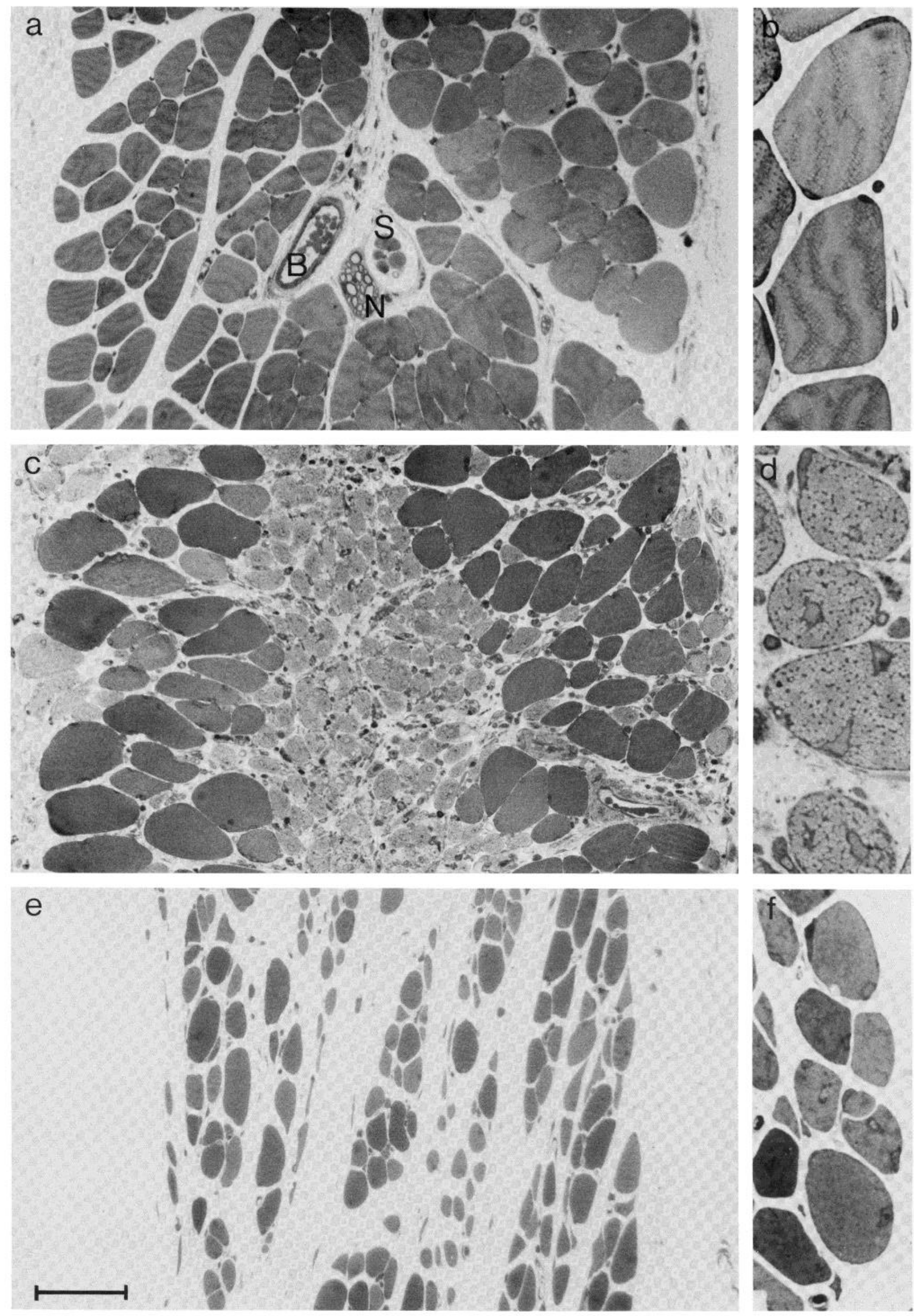

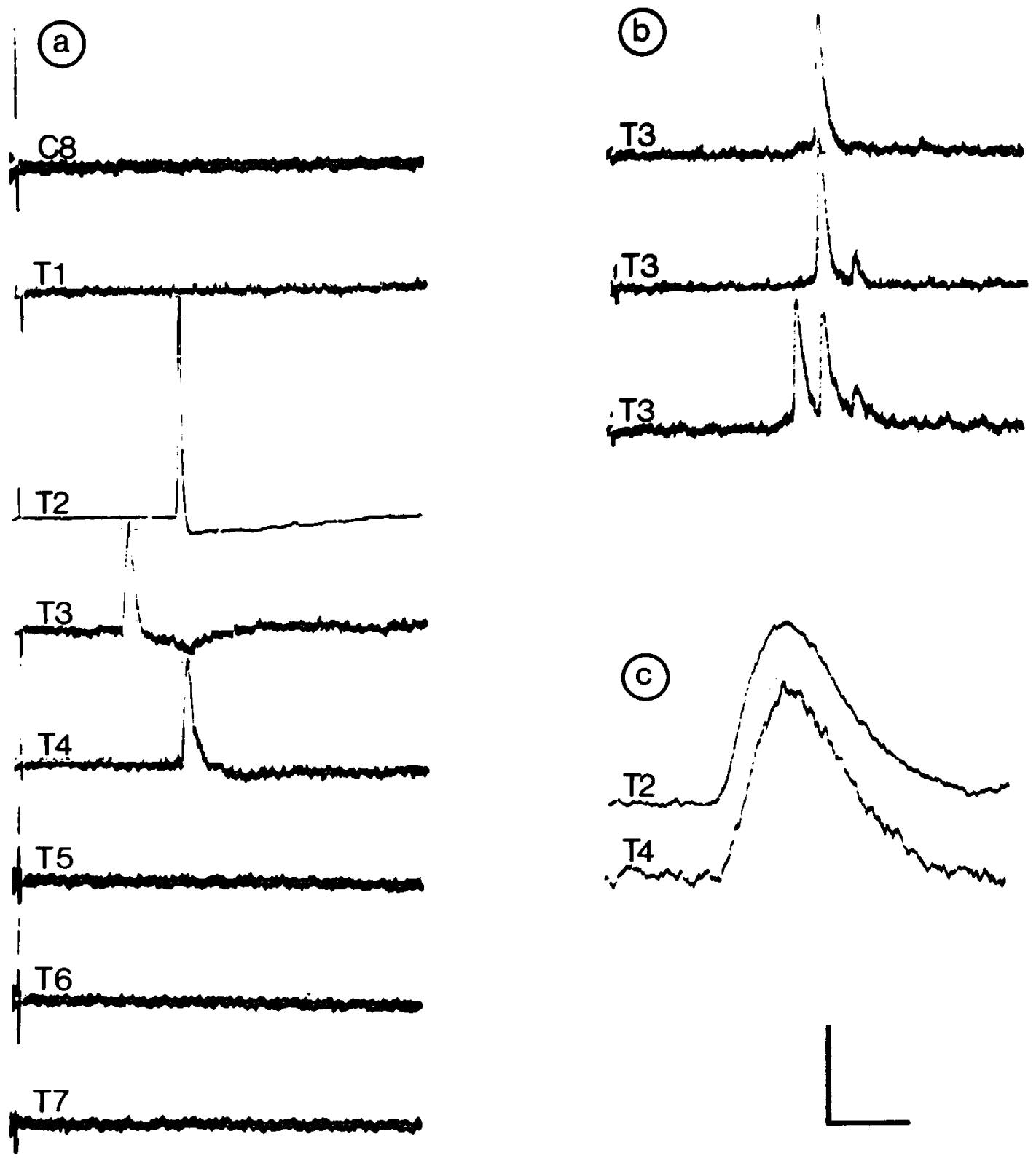

Figure 3. Synaptic potentials recorded intracellularly from transplanted intercostal muscles upon stimulation of the indicated ventral roots. $a$, This muscle fiber received one input from each of three segments. Inputs were suprathreshold from T2 and subthreshold from T3 and T4. b, This fiber received three inputs from a single segment (T3). Stimulus voltage was increased between traces. $c$, Two inputs to a single fiber have similar rise times, indicating that they are approximately equidistant from the recording electrode. The horizontal bar indicates $40 \mathrm{msec}$ for $a$ and $b$ and $10 \mathrm{msec}$ for $c$. The vertical bar indicates $25 \mathrm{mV}$ for the action potential in $a$ and $2 \mathrm{mV}$ for all other traces.

muscle is composed of a thicker, internal and a thinner, external muscle separated by loose connective tissue. The internal intercostal was peeled away, leaving a sheel of exlerral intercostal muscle fibers altached to ribs at both ends. The rat's neck was then incised, and its right cervical trunk and superior cervical ganglion were exposed. The ganglion was removed, and the trunk was dissected caudally past the omohyoid muscle. The external intercostal transplant was sutured by its ribs to the ventral surface of the omohyoid, and the cut end of the cervical trunk was pulled through a small hole made near the edge of the implant.

For transplantation from a donor animal to a separate host, rats of an inbred strain (Wistar-Furth, obtained from Harlan Sprague Dawley, Indianapolis, IN) were used, to avoid rejection of the transplants. A 150- to $200-\mathrm{gm}$ male rat was killed, and large sections of its rib cage were removed aseptically. Smaller pieces were then cut from levels T3, T4, or T5. Two or three such pieces were obtained from each donor. External intercostals were cleaned and implanted into hosts as described above. Donor and hosts were prepared simultaneously, so that intercostals were implanted less than $1 \mathrm{hr}$ after the donor was killed. Rats in this series were coded after surgery such that we were not aware of the segmental origin of the transplanted muscle during subsequent physiological study.

Figure 2. Cross-sections of external intercostal muscles, before and after transplantation. $a$ and $b$, Normal external intercostal is 10 to 20 fibers thick. The adherent internal intercostal muscle has been peeled away. $B$, blood vessel; $N$, intramuscular nerve; $S$, muscle spindle. $c$ and $d, 6$ days after transplantation. Fibers on the surface have survived, while fibers in the center of the graft have degenerated; regeneration of new myotubes $(d)$ has alrcady begun. $e$ and $f, 25$ days after transplantation. Surviving (surface) fibers have atrophied, while regenerated central fibers have matured, reducing obvious differences between surface and central areas. The bar is $60 \mu \mathrm{m}$ for $a$ and $e, 80 \mu \mathrm{m}$ for $c$, and $20 \mu \mathrm{m}$ for $b, d$, and $f$. 


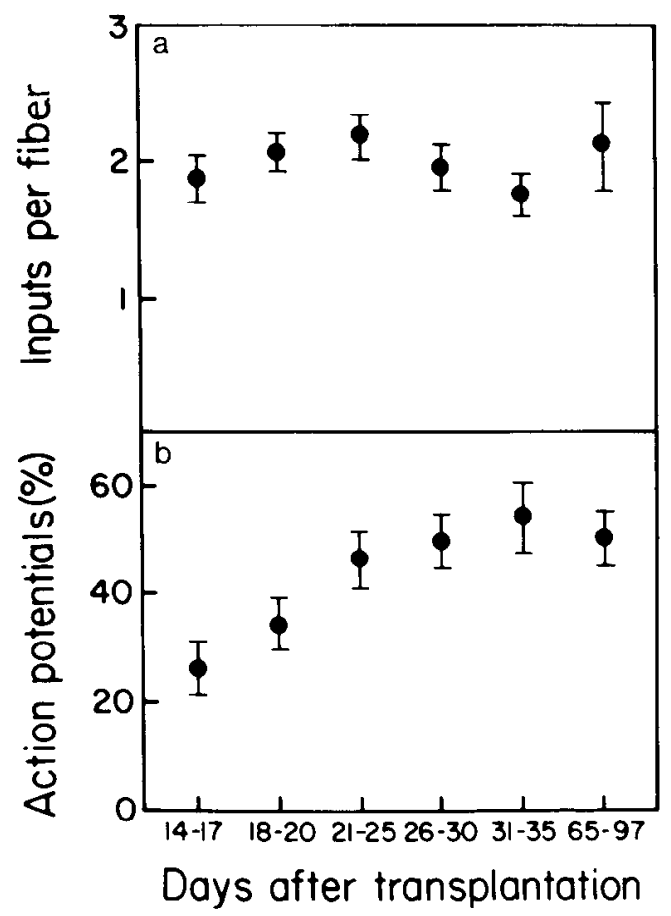

Figure 4. Average number of synaptic inputs per innervated muscle fiber (a), and the percentage of inputs that exceeded threshold and initiated action potentials $(b)$ in muscles tested at varying times after transplantation. Symbols indicate mean; $n=10,14,14,11,7$, and 9 muscles for the six intervals shown. Bars, SE

In some experiments using inbred animals, intercostal muscles were bathed for 20 to $60 \mathrm{~min}$ in a solution of Marcaine (bupivicaine; $0.75 \%$ in isotonic $\mathrm{NaCl}$; Sterling Drugs) instead of saline while being prepared for implantation. Marcaine kills intact muscle fibers but allows new fibers to regenerate (Benoit and Belt, 1970).

Electrophysiology. Rats bearing transplanted intercostals were anesthetized and perfused through the heart with saline. The transplanted muscle cervical trunk, sympathetic ganglion chain, and ventral roots C8 to T7 were dissected in continuity (Fig. 1), mounted in a bath, and superfused with oxygenated saline (Njå and Purves, 1977a). The muscle was pinned to a slab of Sylgard by connective tissue adherent to the ribs, and the ventral roots were pulled into individual suction electrodes. The muscle was transilluminated and viewed with a dissecting microscope while single supramaximal stimuli ( $0.5 \mathrm{msec}$ pulses of 10 to $80 \mathrm{~V}$ ) were delivered to individual ventral roots. The relative vigor of contractions evoked by these stimuli was rated on a scale of 0 to 4 , with 4 being the strongest response in each muscle. The muscle was then stretched beyond its resting length and repinned, to minimize movement during recording.

Intracellular recordings were obtained by impaling muscle fibers near their midpoint with a $3 \mathrm{M} \mathrm{KCl}$-filled microelectrode (15 to 50 megohms). For each fiber impaled that had a resting potential of over $50 \mathrm{mV}$, ventral roots C8 to $T 7$ were stimulated supramaximally in turn at 0.5 or $1 \mathrm{~Hz}$. When a response was seen, the stimulus strength and polarity were varied to discern multiple inputs from a single root (Redfern, 1970). Reinnervation of transplanted muscles seemed to reflect the geometry of nerve growth across the transplant, with the majority of fibers reinnervated in some areas and other large areas not reinnervated at all. Therefore, the electrode was moved across the muscle in steps of $\sim 100 \mu \mathrm{m}$ between recordings, to sample fibers throughout the transplant; often, the muscle was turned over and repinned to sample fibers on both sides of the transplant.

Histology. Either directly after dissection or following recording, muscles were pinned out and fixed in $1 \%$ glutaraldehyde, $2 \%$ paraformaldehyde, 130 $\mathrm{mm} \mathrm{NaCl}$, and $30 \mathrm{~mm}$ HEPES, $\mathrm{pH}$ 7.3. Muscles were then rinsed in saline, stained histochernically for cholinesterase (Karnovsky, 1964) to mark synaplic sites, refixed in $1 \% \mathrm{OsO}_{4}$, dehydrated, and embedded in Araldite. Thick sections $(0.5$ to $1 \mu \mathrm{m})$ were stained with toluidine blue for light microscopy, and thin sections were stained with uranyl acetate and lead citrate for electron microscopy.

\section{Results}

Transplantation and reinnervation of external intercostal muscles. Strips of external intercostal muscle were transplanted to the neck from the 2nd, 3rd, 4th, 5th, or 8th thoracic interspace (Fig. 1). Muscle fibers near the surfaces of the transplants survived, while fibers in the center died and were replaced by regeneration (Fig. 2, a to $d$ ). Regenerated myotubes matured and surviving fibers atrophied, so that the two populations could not readily be distinguished 2 or more weeks after surgery (Fig. 2, $e$ and $f$ ). This sequence of events is similar to that described by Hansen-Smith and Carlson (1979) in transplanted rat extensor digitorum longus muscle, except that since the external intercostal is a thinner muscle, a larger fraction of its fiber are near a free surface and thus survive.

Axons in the cervical sympathetic trunk reinnervated muscle fibers in the transplants within 2 weeks of surgery. Muscles twitched in response to stimulation of the cervical trunk or of individual ventral roots, and postsynaptic potentials could be recorded intracellularly from muscle fibers (Fig. 3). Since sympathetic preganglionics are the only axons in the cervical trunk that run through the ventral roots (Brooks-Fournier and Coggeshall, 1981; Bowers and Zigmond 1981), we assume that responses evoked by stimulating ventral roots represent synapses made by sympathetic preganglionic axoris. Furthermore, these synaptic responses resembled previously described synapses of autonomic preganglionic axons on skeletal muscle fibers (Bennett et al., 1973; Landmesser, 1971, 1972; Grinnell and Rheuben, 1979). Synaptic potentials appeared with a latency of 70 to $200 \mathrm{msec}$ after stimulation, corresponding to a conduction velocity of 0.2 to $0.6 \mathrm{~m} / \mathrm{sec}$, which is characteristic of unmyelinated preganglionic axons (e.g., Wigston, 1983). Responses were reversibly blocked by curare $(0.2$ to $0.5 \mu \mathrm{M})$, indicating that transmission was cholinergic. Synaptic potentials varied greatly in amplitude, sometimes initiated action potentials, and generally fatigued rapidly on repetitive stimulation at $0.5 \mathrm{~Hz}$.

About $60 \%$ (1194 of 1975) of the innervated fibers in transplanted intercostals were polyneuronally innervated. Individual muscle fibers could receive inputs from more than one segment (Fig. 3a) and/or more than one input from a single segment (Fig. 3b). We detected an average of about 2 inputs per innervated fiber (Fig. 4a); the maximum was 7 (11 fibers). Rise times of synaptic potentials recorded from a single fiber were usually indistinguishable (Fig. 3c), indicating that the inputs were approximately equidistant from the recording electrode and thus probably closely spaced. The average number of inputs per innervated fiber changed little between 2 and 6 weeks after transplantation (Fig. $4 a$ ), while the percentage of inputs that were large enough to initiate an action potential doubled (Fig. 4b). It therefore seems likely that muscle fibers acquired nearly their full complement of inputs early in reinnervation and that individual inputs then became stronger during the subsequent few weeks.

Electron microscopy of reinnervated transplanted intercostals revealed conventional neuromuscular synapses, in which vesicle-laden nerve terminals were separated from the muscle fiber membrane by a 50-nm synaptic cleft which was traversed by basal lamina (Fig. 5). The postsynaptic surface was frequently depressed to form junctional folds (Fig. 5a). In many cases, nerve terminals abutted but did not completely cover infolded regions (Fig. 5b) and thus had presumably partially reinnervated a preexisting synaptic site. Since original synaptic sites occupy only a tiny fraction $(\sim 0.1 \%)$ of the muscle fiber surface, this observation indicates that preganglionic axons preferentially formed synapses at such sites. In some cases, however, nerve terminals apposed uninvaginated stretches of muscle membrane (Fig. $5 c$ ), indicating that some completely new synapses were formed during reinnervation of the transplants. Thus, muscle fibers in transplanted intercostals were reinnervated preferentially, although not exclusively, at original synaptic sites.

Segmental origin of inputs to transplanted T2 and T8 intercostal muscles. In one series of experiments, strips of external intercostal muscle were excised from either T2 and T8 and implanted in the 

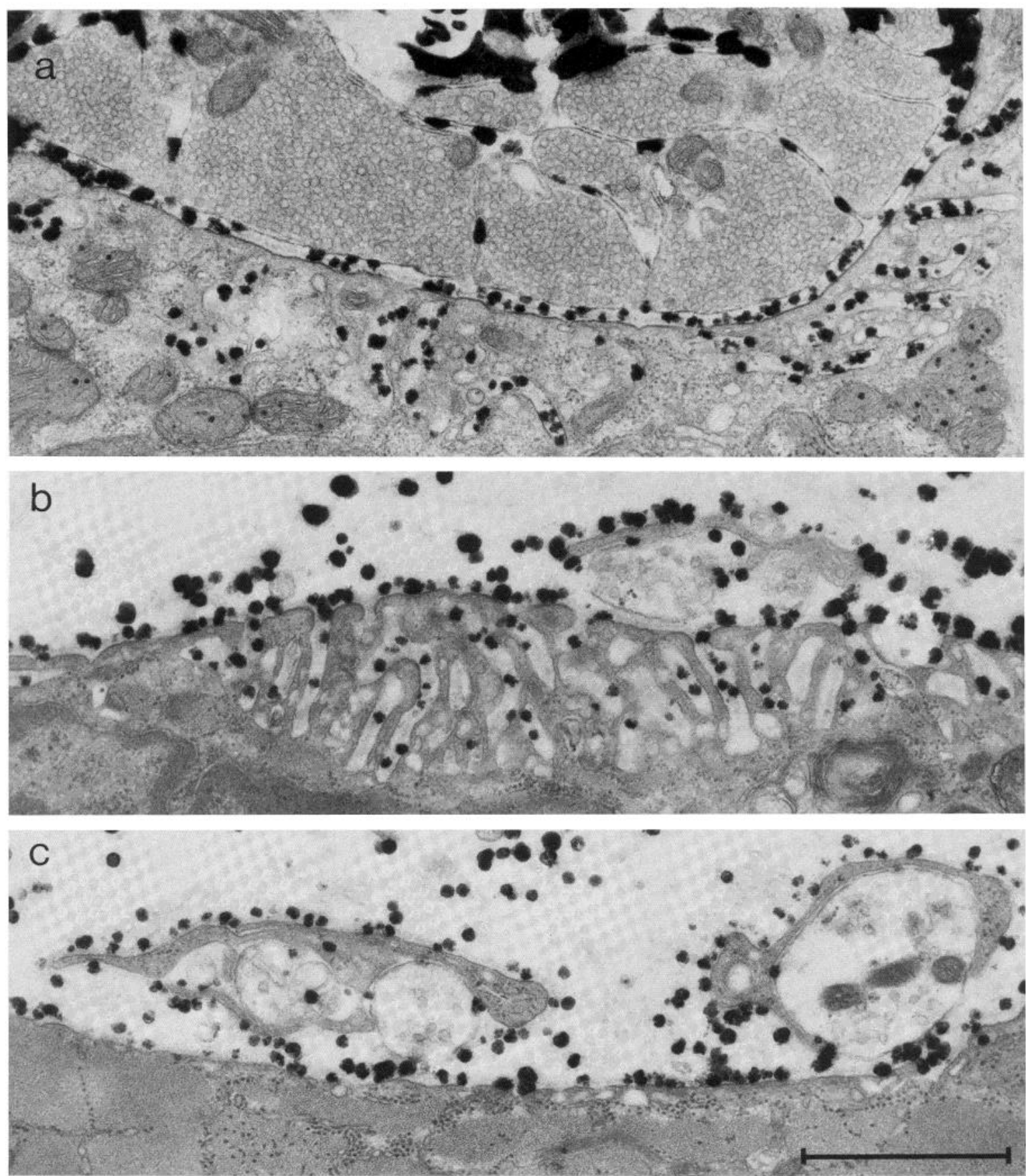

Figure 5. Electron micrographs of neuromuscular junctions in reinnervated, transplanted intercostals, 3 to 4 weeks after surgery. Several terminals share an infolded synaptic area in $a$. The nerve terminal in $b$ covers part of a folded patch and thus has apparently reinnervated an original synaptic site. The terminal in $c$ abuts undifferentiated postsynaptic membrane and thus presumably has established a new synaptic site. Black spots are reaction product of the histochemical stain for cholinesterase, which was used to facilitate localization of synaptic sites. Bar, $1 \mu \mathrm{m}$. 
TABLE I

Reinnervation of transplanted $T 2$ and $T 8$ external intercostal muscles by the cervical sympathetic trunk

\begin{tabular}{|c|c|c|c|c|}
\hline & \multicolumn{2}{|c|}{ Two to Four Weeks after Transplantation } & \multicolumn{2}{|c|}{ Ten to 14 Weeks after Transplantation } \\
\hline & $\mathrm{T} 2$ & T8 & $\mathrm{T} 2$ & T8 \\
\hline Number of muscles & 11 & 12 & 4 & 5 \\
\hline Time after surgery (days) & $19 \pm 1$ & $20 \pm 1$ & $79 \pm 7$ & $80 \pm 5$ \\
\hline Innervated fibers studied & 346 & 342 & 110 & 143 \\
\hline Total inputs & 789 & 621 & 235 & 331 \\
\hline Inputs/innervated fiber ${ }^{(1) b}$ & $2.2 \pm 0.2$ & $1.8 \pm 0.1$ & $2.1 \pm 0.2$ & $2.2 \pm 0.5$ \\
\hline \multicolumn{5}{|l|}{ Average segmental innervation ${ }^{c}$} \\
\hline All inputs ${ }^{(2)}$ & $2.32 \pm 0.07^{a}$ & $2.76 \pm 0.09$ & $2.35 \pm 0.13$ & $2.76 \pm 0.12$ \\
\hline Suprathreshold inputs ${ }^{(3)}$ & $2.22 \pm 0.08$ & $2.80 \pm 0.16$ & $2.28 \pm 0.15$ & $2.77 \pm 0.14$ \\
\hline Visible contractions $^{(4)}$ & $2.52 \pm 0.09$ & $2.83 \pm 0.13$ & $2.40 \pm 0.15$ & $2.71 \pm 0.11$ \\
\hline
\end{tabular}

a Mean \pm SE of values calculated separately for each muscle.

${ }^{h}$ Significance of differences by the Student's $t$ test:

(1) T2a-T8a, $\rho=0.1$; T2b-T8b, T2a-T2b, T8a-T8b, all $\rho>0.4$.

(2) T2a-T8a, $p<0.001$; T2b-T8b, $p<0.05$; T2a-T2b, T8a-T8b, both $p>0.9$

(3) T2a-T8a, $p<0.01$; T2b-T8b, $\rho<0.05$; T2a-T2b, T8a-T8b, both $p>0.8$.

(4) T2a-T8a, $\rho<0.1$; T2b-T8b, $\rho<0.2$; T2a-T2b, T8a-T8b, both $\rho>0.4$.

"Calculated as described under "Results" and shown in Figure 7; lower values reflect a rostral and higher values a caudal bias to the innervation.

Figure 6. Segmental origin of synaptic inputs to transplanted T2 and T8 intercostal muscles, studied 2 to 4 weeks after surgery. $a$, Distribution of all inputs recorded intracellularly. $b$, Distribution of suprathreshold inputs-i.e., those that initiated muscle action potentials. See Table I, left columns for numbers of muscles, muscle fibers, and inputs studied.

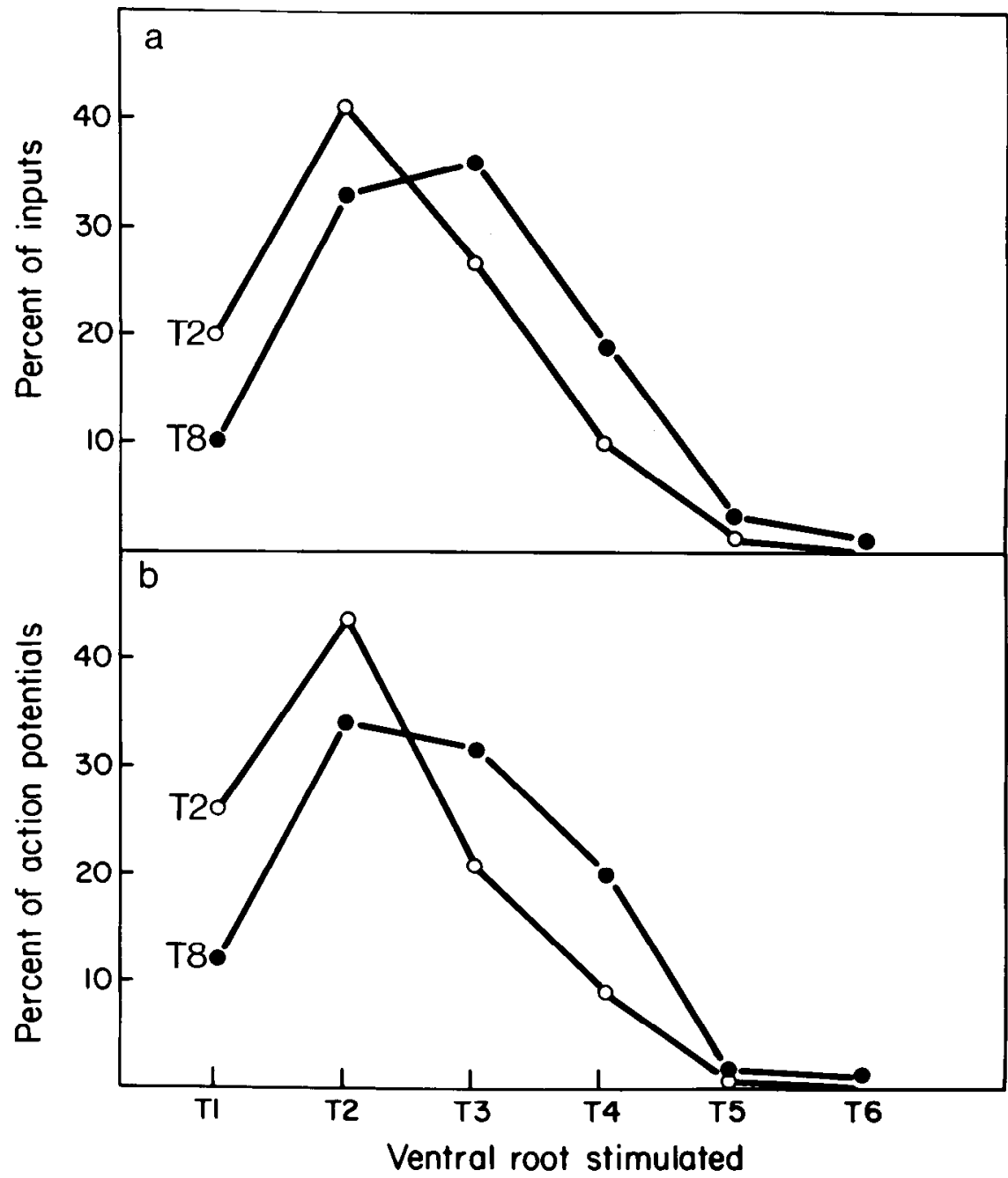

ncck of the same rat. Transplanted T2 and T8 muscles were reinnervated to a similar extent (Table I, left columns) but differed in the segmental origin of their inputs. T2 muscles received a larger fraction of their inputs from segments T1 and T2 than did T8 muscles, and T8 muscles received a larger fraction of their inputs from segments T3 to T6 than did T2 muscles (Fig. 6a). Differences between $\mathrm{T} 2$ and $\mathrm{T} 8$ intercostals were also evident when we considered only suprathreshold inputs, which initiated action potentials 


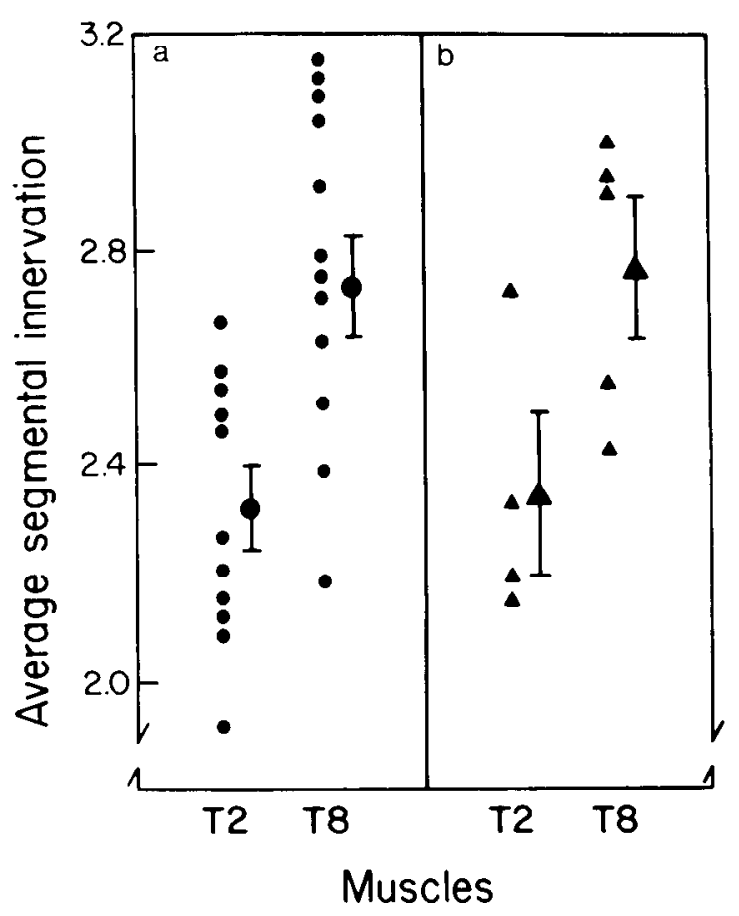

Figure 7. Average segmental innervation of transplanted $\mathrm{T} 2$ and $\mathrm{T} 8$ intercostals. This index, calculated as described under "Results," is the segmentally weighted average of all synaptic inputs recorded intracellularly from the muscle fibers of a transplant. Thus, the higher a muscle's value, the more caudal, on average, was its innervation. Small symbols represent individual muscles, and large symbols show mean of groups; bars, SE. a, Muscles studied 2 to 4 weeks after transplantation (see Table I, left columns). $b$, Muscles studied 10 to 14 weeks after transplantation (see Table I, right columns).

(Fig. 6b). Since action potentials propagate along muscle fibers, this result indicates that our detection of selective reinnervation was not affected by any possible failure to record small (low amplitude or electrotonically distant) inputs. Thus, on average, T2 muscles were reinnervated by a relatively rostral and $\mathrm{T} 8$ muscles by a relatively caudal subset of preganglionic axons.

The segmental innervation of individual muscles in this series is displayed in Figure $7 \mathrm{a}$. To construct this figure, we calculated an index for each muscle that reflects the average segmental origin of all inputs recorded from it. For example, a hypothetical transplant in which we recorded 10 inputs each from axons in ventral roots T1, $\mathrm{T} 2$, and T4 would receive a value of $[(1 \times 10)+(2 \times 10)+(4 \times$ $10)] / 30=2.33$. Thus, the muscle reinnervated by the most caudally derived set of axons received the highest index of segmental innervation. In 23 experiments, 9 of the 10 highest values were from T8 muscles, and 8 of the 10 lowest values were from T2 muscles (Fig. 7a). Similar indices calculated using only suprathreshold inputs, or using visual estimates of contractile strength (see "Materials and Methods") also gave higher average values for T8 muscles than for T2 muscles (Table I), and in each case, 8 of the 10 highest values were from T8 muscles and 8 of the 10 lowest values were from T2 muscles. Thus, the segmental preferences of groups did not merely reflect the disproportionate contribution of a few aberrant muscles. Instead, most T2 muscles were reinnervated more effectively by rostrally derived axons than were most T8 muscles.

Segmental origin of inputs to long-term transplants. The results presented in the preceding section were obtained from muscles studied 2 to 4 weeks (mean $=20$ days) after transplantation, a period during which the average strength of inputs was increasing (Fig. 4b). To determine whether selectivity was evident only during this early stage of reinnervation, we studied the segmental origin of inputs to a group of T2 and T8 muscles at 10 to 14 weeks (mean $=80$ days) after transplantation. At this later stage, T2 muscles were still innervated preferentially by rostrally derived and $T 8$ muscles by caudally derived axons (Figs. $7 b$ and 8 and Table I, right columns). The difference between $\mathrm{T} 2$ and $\mathrm{T} 8$ muscles was equivalent in the 2- to 4-week and the 10- to 14-week groups (compare Table l, left columns and right columns). Thus, neither the existence nor the magnitude of the difference between T2 and T8 muscles was peculiar to an early stage of reinnervation.

Segmental origin of inputs to transplanted T3, T4, and T5 intercostal muscles. In a second series of experiments, we determined the segmental origin of inputs to transplanted T3, T4, and T5 external intercostal muscles. This tested whether axons could distinguish muscles from adjacent segments and also whether the selectivity observed in the first series reflected some property peculiar to either T2 or T8 muscles. For this series, we transplanted muscles from the rib cage of one animal to the neck of another, using inbred rats to avoid rejection of the implant. The use of separate donors and hosts eliminates complications arising from thoracic surgery (e.g., axotomy of intercostal motoneurons) and facilitated subsequent experiments in which muscules were incubated with a toxin before being reimplanted (see below).

Transplanted T3, T4, and T5 intercostals differed systematically in their segmental innervation. While muscles from all three segments were reinnervated to a similar extent (Table II), T3 muscles were reinnervated by a relatively rostral, $T 4$ muscles by an intermediate, and T5 muscles by a relatively caudal subset of preganglionic axons. This selectivity was evident whether reinnervation was assessed by all inputs recorded intracellularly, by only suprathreshold inputs, or by visual estimates of the vigor of contractions evoked by stimulating individual ventral roots (Figs. 9 and 10, Table II).

The difference between T3 and T5 muscles observed in this series was nearly equivalent to the difference between T2 and T8 muscles in the first series. These results might reflect either a limited extent of differences among segmental muscles or limits to the detection of differences by preganglionic axons. However, the use of different strains of rats and surgical protocols prevents any strict comparison of the two series. Nonetheless, in each series considered separately, there was a correspondence between a transplanted muscle's position of origin along the rostrocaudal axis and the segmental origin of the inputs it received.

Segmental origin of inputs to regenerated intercostals. As noted above, some intercostal muscle fibers survived transplantation, while others died and were replaced by regeneration (Fig. 2). The fraction of fibers that survived varied considerably from muscle to muscle, and we were unable to determine which recordings were obtained from surviving and which from regenerated fibers. It was therefore possible that the segmental preferences we observed reflected selective reinnervation of either population or of both. As one test of these alternatives, we assessed the reinnervation of transplanted T3 and $T 5$ intercostals that contained all regenerated and no surviving fibers. To deplete the transplants of surviving fibers, we soaked them in Marcaine, a local anesthetic and myotoxin. Although Marcaine kills muscle fibers, it spares other cells, including the satellite cells responsible for muscle regeneration after injury (Benoit and Belt, 1970; Jirmanova and Thesleff, 1972). The extent and time course of muscle regeneration are reported to be identical in Marcaine-treated and untreated grafts (Carlson, 1976; Hansen-Smith and Carlson, 1979). When we soaked external intercostals in Marcaine before implanting them in the neck, no muscle fibers survived (Fig. 11, $a$ and b). Subsequently, muscle fibers regenerated throughout the muscle (Fig. 11, $c$ and $d$ ). On average, we found Marcainetreated transplants to be somewhat thinner than untreated transplants and to contain slightly smaller fibers (fiber diameter, $12.0 \pm$ $1.7 \mu \mathrm{m}$ in untreated and $10.2 \pm 1.8 \mu \mathrm{m}$ in Marcaine-treated transplants; mean \pm SE from 7 muscles in each group). There were, 
Figure 8 . Segmental origin of synaptic inputs to T2 and $\mathrm{T} 8$ intercostals studied 10 to 14 weeks after transplantation (see Table I, right columns). a, Distribution of all inputs recorded intracellularly. $b$, Distribution of suprathreshold inputs.

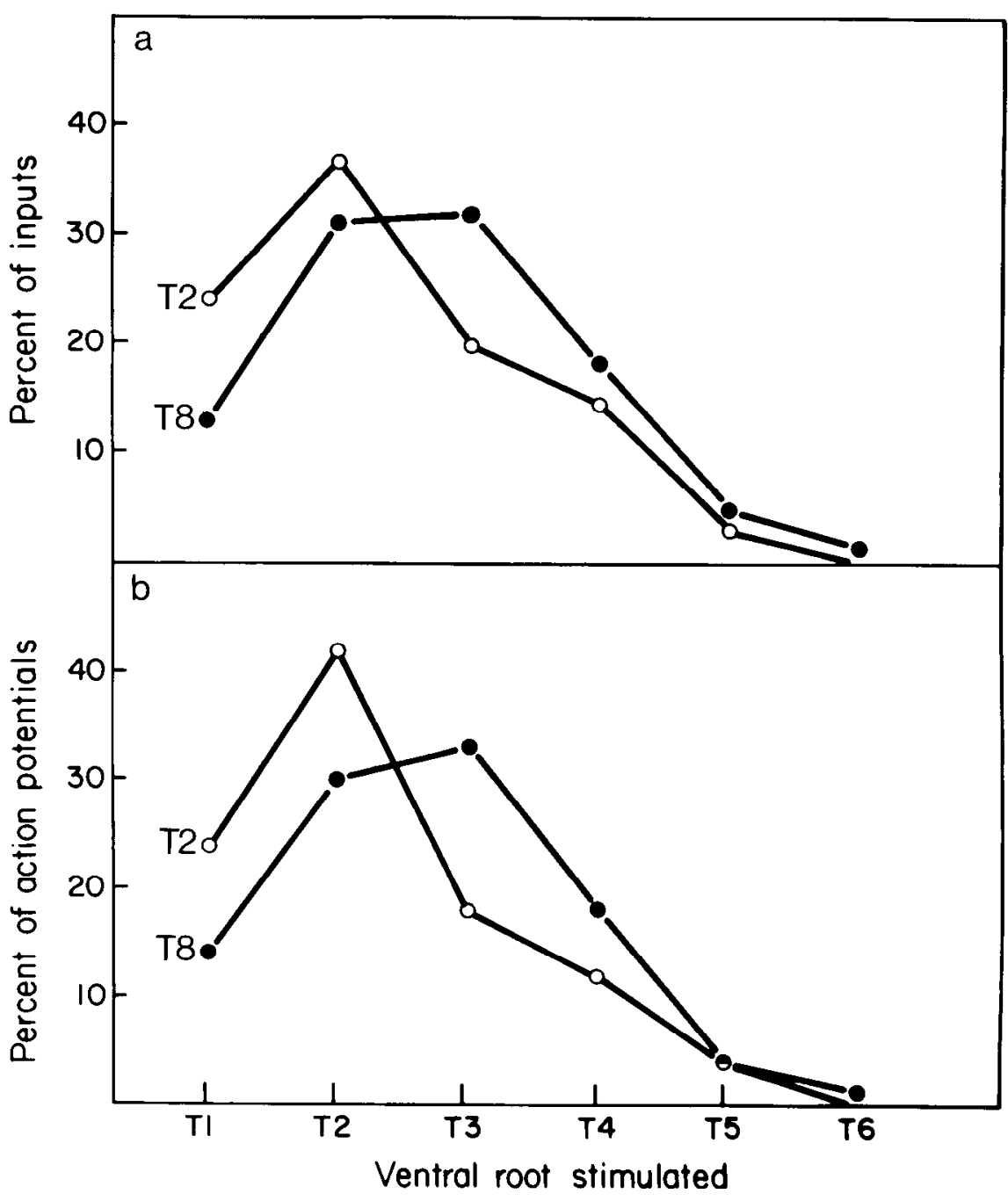

TABLE \|

Reinnervation of transplanted $T 3, T 4$, and $T 5$ external intercostal muscles by the cervical sympathetic trunk

\begin{tabular}{llll}
\hline & \multicolumn{3}{c}{ Muscle } \\
\cline { 2 - 4 } & \multicolumn{1}{c}{ T3 } & \multicolumn{1}{c}{ T4 } & T5 \\
\hline Number of muscles & 11 & 10 & 12 \\
Time after surgery (days) & $27 \pm 2$ & $27 \pm 1$ & $23 \pm 3$ \\
Innervated fibers studied & 320 & 320 & 395 \\
Total inputs $^{\text {Inputs/innervated fiber }}{ }^{(1) b}$ & 706 & 661 & 745 \\
Average segmental innervation $^{c}$ & $2.1 \pm 0.2$ & $2.0 \pm 0.2$ & $1.9 \pm 0.1$ \\
All inputs $^{(2)}$ & $2.30 \pm 0.09^{a}$ & $2.59 \pm 0.10$ & $2.89 \pm 0.10$ \\
Suprathreshold inputs $^{(3)}$ & $2.24 \pm 0.09$ & $2.45 \pm 0.10$ & $2.94 \pm 0.14$ \\
Visible contractions $^{(4)}$ & $2.59 \pm 0.05$ & $2.62 \pm 0.07$ & $2.89 \pm 0.10$ \\
\hline
\end{tabular}

${ }^{a}$ Mean \pm SE of values calculated separately for each muscle.

${ }^{D}$ Significance of differences by the Student's $t$ test:

(1) T3-T4, T4-T5, T3-T5, all $\rho>0.4$.

(2) T3-T4, $p<0.05$; T4-T5, $p<0.05$; T3-T5, $p<0.001$.

(3) T3-T4, $p<0.1$; T4-T5, $p<0.01$; T3-T5, $p<0.001$.

(4) T3-T4, $p>0.5$; T4-T5, $p<0.05$; T3-T5, $p<0.02$.

${ }^{c}$ Calculated as described under "Results" and shown in Figure 10; lower values reflect a rostral and higher values a caudal bias to the innervation. This does not include one T3 and one T5 muscle in which $<10$ fibers were studied. however, no marked histological differences between untreated and Marcaine-treated transplants by 3 to 4 weeks after surgery.

Marcaine-treated transplants were successfully reinnervated by preganglionic axons in the cervical trunk. Marcaine-treated and untreated transplants differed little in the overall extent of their innervation (compare Tables II and III). In contrast to results obtained from untreated transplants, however, Marcaine-treated T3 and T5 intercostals did not differ significantly in the segmental origin of their inputs (Fig. 12 and Table III). Neither intracellular recording nor estimates of contractile vigor revealed any preference of rostral axons for T3 muscles or of caudal axons for T5 muscles. Thus, muscles that were forced to regenerate before they were reinnervated were not distinguished by preganglionic axons from different segmental levels.

\section{Discussion}

External intercostal muscles can be reinnervated by the sympathetic preganglionic axons of the cervical trunk. Intercostals from each of several levels are reinnervated to a similar extent (Tables I and II) but differ in the segmental distribution of the inputs they receive. Transplanted $\mathrm{T} 2$ intercostals receive more inputs from rostral and fewer from caudal segments than do T8 intercostals (Figs. 6 to 8). Similarly, T3 muscles are reinnervated by a relatively rostral, T4 muscles by an intermediate, and T5 muscles by a relatively caudal subset of axons (Fig. 9 and 10). Together, these results demonstrale 


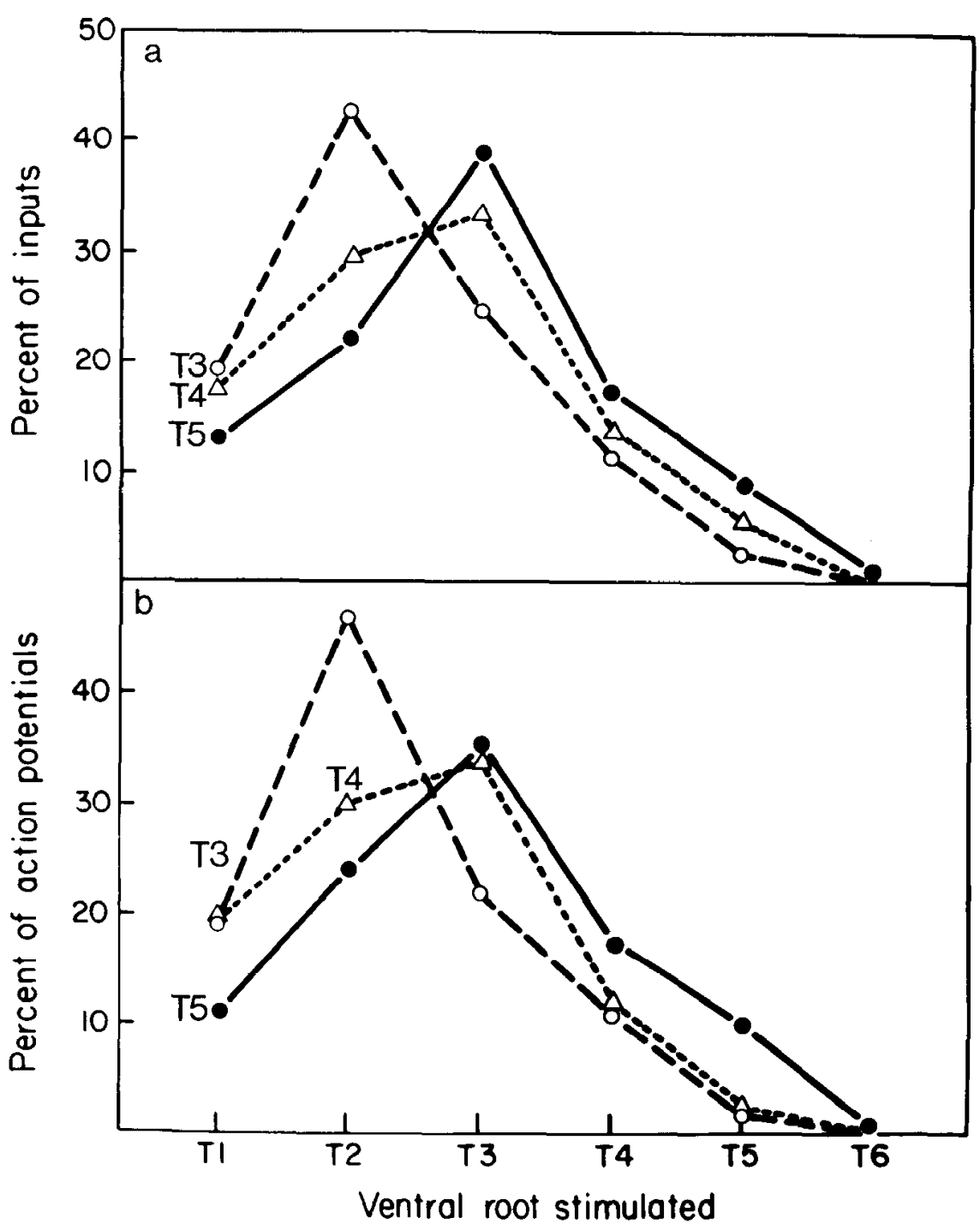

Figure 9. Segmental origin of synaptic inputs to the transplanted T3, T4, and T5 intercostal muscles described in Table II. a, Distribution of all inputs recorded intracellularly. $b$, Distribution of suprathreshold inputs. 


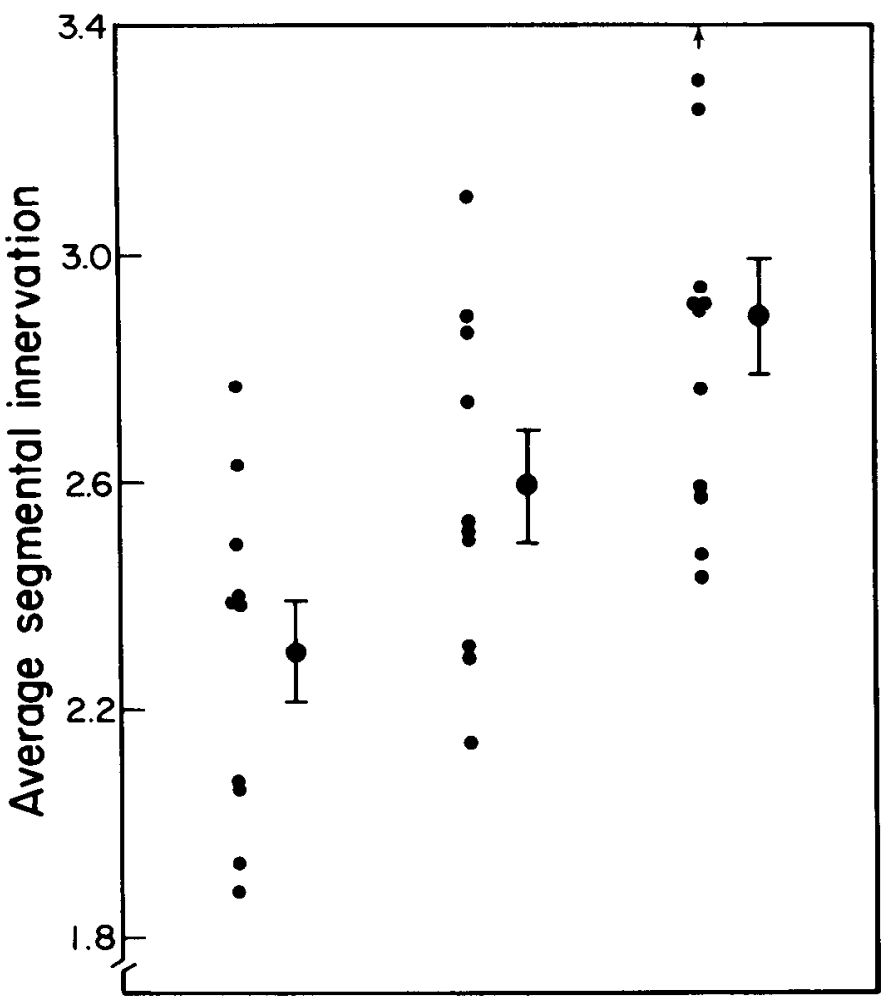

$\begin{array}{lll}\text { T3 } & \text { T4 } & \text { T5 }\end{array}$

\section{Transplanted muscle}

Figure 10. Average segmental innervation of transplanted T3, T4, and T5 intercostals (see Table II). Small circles represent individual muscles, and large circles show mean of groups; bars, SE. Arrow indicates one muscle with a value of 3.63 .

that adult mammalian muscles can be selectively reinnervated, possibly on the basis of some quality associated with their position of origin in the body's rostrocaudal axis.

Selective reinnervation of transplanted intercostals. The selective reinnervation we observed contrasts with results of several previous studies, in which reinnervation of adult rat muscles was shown to be nonselective (Weiss and Hoag, 1946; Bernstein and Guth, 1961; Miledi and Stefani, 1969; Gerding et al., 1977; Riley, 1978; Brushart and Mesulam, 1980; Gillespie et al., 1983; but see Hoh, 1975). However, our experiments differed from other studies in several ways that may have favored the detection of selectivity. First, previous experiments were not designed to assess differences among axons or muscles that reflected their position in the rostrocaudal axis. Thus, nerves that competed with equal success for limb muscles contained axons from overlapping sets of spinal segments (e.g., Weiss and Hoag, 1946; Gerding et al., 1977). Even when the segmental origin of reinnervating axons was determined (Bernstein and Guth, 1961; Brushart and Mesulam, 1980), the experiments compared reinnervation of two muscles that are normally innervated from, and may themselves arise from (Chevallier et al., 1977) the same segments. Recent studies of synapse elimination in neonatal rat muscles indicate that appropriate tests carr reveal segmental preferences of axons for different portions of limb muscles (Brown and Booth, 1983; Bennett and Lavidis, 1984).

Second, in several previous studies, nerves were injured far from the muscles the reinnervation of which was assessed (Weiss and Hoay, 1946; Berrislein and Gulh, 1961; Miledi and Slelani, 1969; Brushart and Mesulam, 1980). Nonselective regeneration of axons along pathways to the muscle may have masked selectivity within the muscle itself. In contrast, in our experiments, implantation of the cervical trunk provided axons from many segments with direct access to the target muscle.

Third, our experiments made use of, and our results may have depended on, the juxtaposition of sympathetic preganglionic axons with skeletal muscles. Preganglionic axons are known to selectively reinnervate subsets of sympathetic ganglionic neurons (see the introduction) and may reveal differences among muscles that adult motor axons ignore. Furthermore, while preganglionic axons are able to innervate skeletal muscles, the synapses they form are, on average, weaker than those formed by regenerating motor axons (Landmesser, 1971; Bennett et al., 1973; Grinnell and Rheuben, 1979; Gordon et al., 1980). It is possible that relative preferences of axons for particular muscles can be detected only when a strong attraction of all motor axons for all muscles is circumvented.

While reinnervation of intercostal muscles was demonstrably selective, there was no absolute preference of axons from any ventral rool for muscles from any thoracic level. There are, however, two factors that may have reduced the degree of selectivity manifested in our experiments. First, while the rat's cervical trunk contains axons from six to eight levels (Rando et al., 1981; Murata et al., 1982), the normal innervation of the superior cervical ganglion is derived predominantly from $\mathrm{T} 2$ and $\mathrm{T} 3$ (J. Lichtman, personal communication; see also Njå and Purves, $1977 \mathrm{a}, \mathrm{b})$. Thus, preferences of muscles for rostral or caudal axons might have been balanced against the far greater availability of axons from middle segments. Purves et al. (1981) have made a similar argument in discussing the selective reinnervation of sympathetic ganglia transplanted from different levels. A second possibility is that a more selective reinnervation of surviving muscle fibers in the transplants was masked by nonselective reinnervation of regenerated fibers.

Nonselective reinnervation of regenerated muscle fibers. While many muscle fibcrs survived transplantation to the neck, a large and variable number died and were replaced by regeneration, presumably from myoblastic satellite cells within the muscle (see Allbrook, 1981; Carlson and Faulkner, 1983, for reviews). To determine whether surviving or regenerated fibers are selectively reinnervated, one needs to study each population separately. We have not so far been able to distinguish surviving from regenerated fibers after reinnervation or to prevent fiber death and regeneration. However, we were able to prepare pure populations of regenerated fibers by soaking muscles in Marcaine before reimplanting them. This drug kills muscle fibers but does not impair the ability of satellite cells to divide, fuse, and differentiate to form new myotubes (Benoit and Belt, 1970; Jirmanova and Thesleff, 1972; Carlson, 1976; HansenSmith and Carlson, 1979). We tound that regenerated fibers in Marcaine-treated T3 and T5 transplants were successfully but nonselectively reinnervated by preganglionic axons.

We do not know why regenerated muscles fail to select among (or be selected by) preganglionic axons. Perhaps the most likely possibility is that some cues used by axons are associated with muscle fibers and are lost when muscle fibers die. For example, differences among muscles that axons recognize might not be expressed by myotubes that form postembryonically or in an abnormal location. It is also possible, however, that cues persist but are inaccessible in regenerated muscle. For example, cues located in the basal lamina of original synaptic sites (e.g., Sanes et al., 1978) might survive muscle degeneration but would not be encountered by axons that form synapses at completely new sites; such ectopic synapses are known to form in regenerating mammalian muscle (Fig. 5c; see also Ontell et al., 1982; Hansen-Smith, 1983). Another possibility is that recognition cues are destroyed by an unknown action of Marcaine separate from its myotoxicity. Some of these alternatives could be distinguished by determining whether preganglionic axons selectively reinnervate muscles that are caused to degenerate and regenerate in situ before they are excised and reimplanted. 

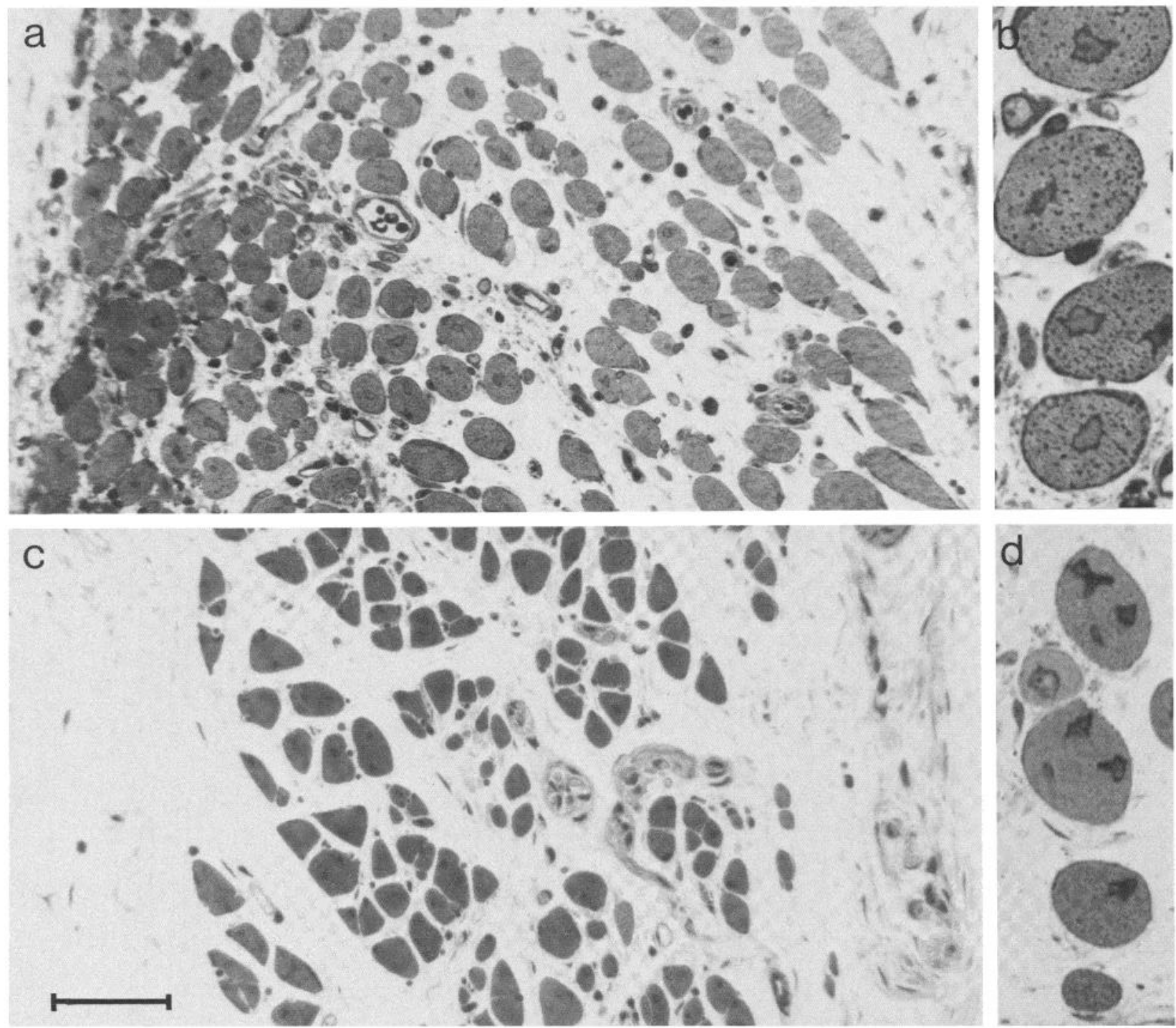

Figure 11. Degeneration and regeneration of intercostal muscles soaked in the myotoxin Marcaine and then transplanted to the neck. $a$ and $b, 6$ days after transplantation. No fibers survived; regeneration is in progress throughout the muscle (compare Fig. $2 c$ and $d$ ). $c$ and $d, 32$ days after transplantation. Note central nuclei, which are characteristic of regenerating fibers (compare Fig. 2, e and $f$ ). The bar is $60 \mu \mathrm{m}$ for $a$ and $c$ and $20 \mu \mathrm{m}$ for $b$ and $d$.

TABLE III

Reinnervation of transplanted T3 and T5 Marcaine-treated external intercostal muscles by the cervical sympathetic trunk

\begin{tabular}{lcc}
\hline & \multicolumn{2}{c}{ Muscle } \\
\cline { 2 - 3 } & \multicolumn{1}{c}{ T3 } & T5 \\
\hline Number of muscles & 9 & 10 \\
Time after surgery (days) & $35 \pm 1$ & $33 \pm 2$ \\
Innervated fibers studied & 265 & 219 \\
$\quad$ Total inputs & 491 & 390 \\
Inputs/innervated fiber $^{(1) b}$ & $1.8 \pm 0.1$ & $1.6 \pm 0.2$ \\
Average segmental innervation $^{c}$ & & \\
All inputs $^{(2)}$ & $2.58 \pm 0.12^{a}$ & $2.41 \pm 0.13$ \\
Suprathreshold inputs $^{(3)}$ & $2.50 \pm 0.19$ & $2.28 \pm 0.12$ \\
Visible contractions $^{(4)}$ & $2.67 \pm 0.05$ & $2.55 \pm 0.09$ \\
\hline
\end{tabular}

${ }^{a}$ Mean $\pm \mathrm{SE}$ of values calculated separately for each muscle.

${ }^{D}$ Significance of differences by the Student's $t$ test:

(1) $p>0.3$; (2) $p>0.2$; (3) $p>0.3$; (4) $p>0.2$.

"Calculated as described under "Results" and shown in Figure 12b; lower values reflect a rostral and higher values a caudal bias to the innervation. This does not include one T3 and one T5 muscle in which $<10$ fibers were studied.
A positional basis for selective synapse formation. A single factor that accounts for the selective synapse formation we have observed is the corresponding site of origin of the synaptic partners. What underlies this positional matching? One possibility is that selectivity is based on differences among axons and muscles that are not directly related to their position. For example, intercostal muscles from different levels differ functionally to some extent (Duron, 1981), and we have recently found that external intercostals vary from level to level in their proportions of fast- and slow-twitch fibers (J. R. Sanes and J. M. Cheney, unpublished data). Thus, preganglionic axons from different levels could vary in their preference for muscle fibers of different types, a possibility that we can investigate.

An alternative hypothesis is that the synaptic selectivity we observe is a direct reflection of positional attributes that match axons and muscles from the same segmental level. The idea that developing tissues acquire, maintain, and use a sense of their relative positions within the body-that is, positional information-is an attractive one that has been postulated to account for many aspects of pattern formation during embryogenesis and regeneration (see Wolpert, 1981 and Bryant et al., 1981 for reviews). Within the nervous system, shared or complementary positional labels on axons and targets seem likely to regulate the formation of orderly synaptic arrays. Examples are the "mapping" of retinal axons onto the optic 
Figure 12. Segmental origin of inputs to T3 and T5 intercostal muscles that were soaked in Marcaine before transplantation (see Table III). a, Distribution of inputs evoked by stimulation of the indicated ventral root. $b$, Average segmental innervation of transplanted muscles. Small circles represent individual muscles, and large circles show mean of groups: bars, SE. The arrow represents one muscle with a value of 3.43. Values for muscles transplanted without Marcaine treatment are redrawn from Figure 10
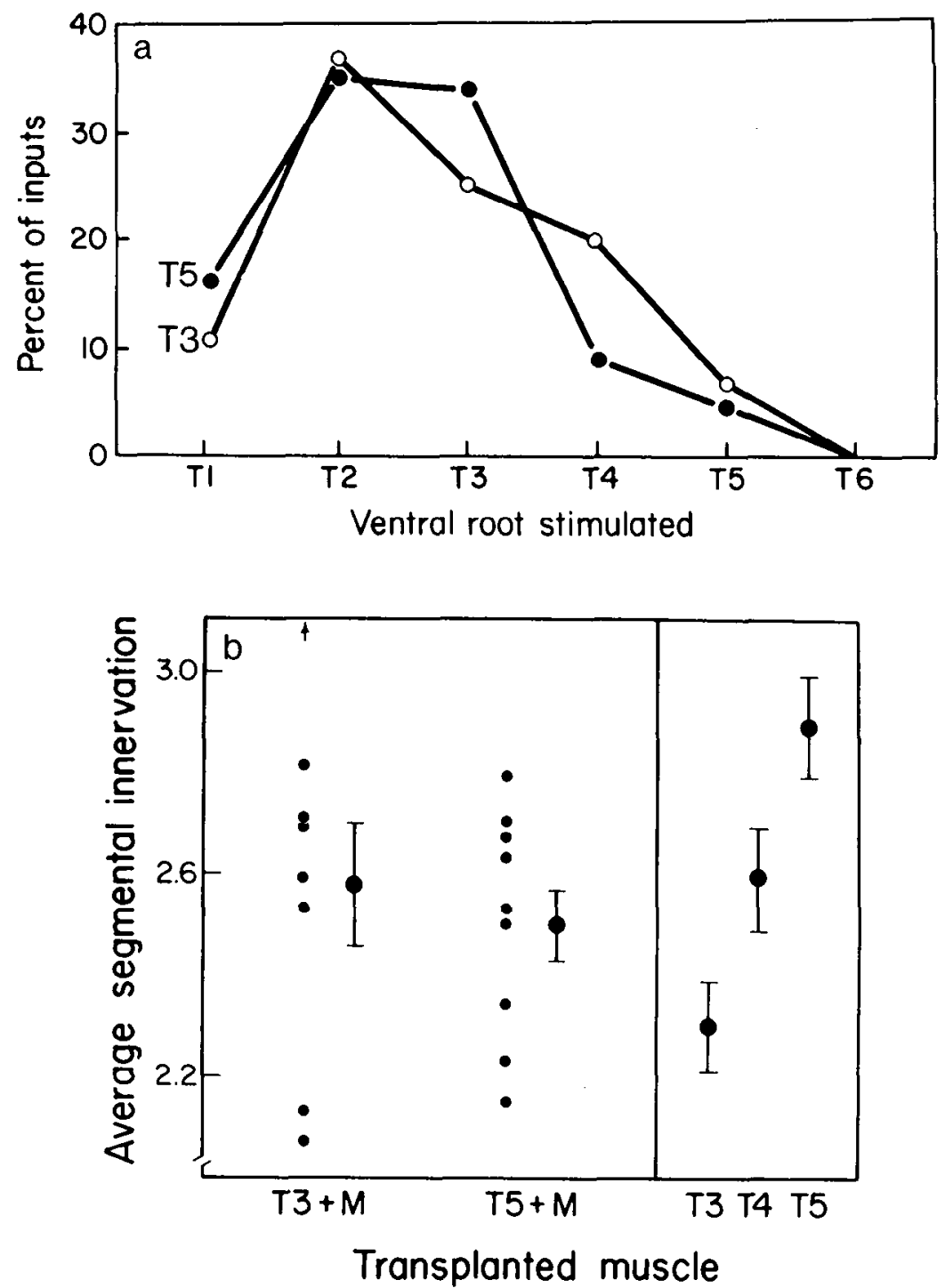

tectum (Sperry, 1963) and the apparently positional matching of preand postganglionic sympathetic neurons (Purves et al., 1981; see also Lichtman et al., 1979) that motivated our work. Our results, together with those of Purves et al. (1981), who showed that transplanted thoracic or lumbar ganglia are reinnervated by more caudally derived preganglionic axons than are reimplanted superior cervical ganglia, suggest the existence of labels that vary in amount or type along the rostrocaudal axis and promote the formation of synapses among positionally matched cells. The recognition between functionally inappropriate synaptic partners-skeletal muscles and autonomic axons-raises the possibility that a single system of such labels is used by several tissues in the body.

\section{References}

Allbrook, D. (1981) Skeletal muscle regeneration. Muscle Nerve 4: 234-245. Bennett, M. R. and N. A. Lavidis (1984) Development of the topographical projection of motor neurons to a rat muscle accompanies less of polyneuronal innervation. J. Neurosci. 4: 2204-2212.

Bennett, M. R., E. M. McLachlan, and R. S. Taylor (1973) The formation of synapses in mammalian striated muscle reinnervated with autonomic preganglionic nerves. J. Physiol. (Lond.) 233: 501-517.

Benoit, P. W. and W. D. Belt (1970) Destruction and regeneration of skeletal muscle after treatment with a local anesthetic, bupivocaine (Marcaine). J. Anat. 107: 547-566.

Bernstein, J. J. and L. Guth (1961) Nonselectivity in the establishment of neuromuscular connections following nerve regeneration in the rat. Exp. Neurol. 4: 262-275.
Bowers, C. W. and R. E. Zigmond (1981) Sympathetic neurons in lower cervical ganglia send axons through the superior cervical ganglion. Neuroscience 6: 1783-1791.

Brodal, A. (1981) Neurological Anatomy in Relation to Clinical Medicine, p. 176, Oxford University Press, New York.

Brooks-Fournier, R. and R. E. Coggeshall (1981) The ratio of preganglionic axons to postganglionic cells in the sympathetic nervous system of the rat. J. Comp. Neurol. 197: 207-216.

Brown, M. C. and C. M. Booth (1983) Postnatal development of the adult pattern of motor axon distribution in rat muscle. Nature 304: 741-742.

Brushart, T. M. and M.- M. Mesulam (1980) Alteration in connections between muscle and anterior horn motoneurons after peripheral nerve repair. Science 208: 603-605.

Bryant, S. V., V. French, and P. J. Bryant (1981) Distal regeneration and symmetry. Science 212: 993-1002.

Carlson, B. M. (1976) An quantitative study of muscle fiber survival and regeneration in normal, predenervated, and Marcaine-treated free muscle grafts in the rat. Exp. Neurol. 52: 421-432. fibers following injury: a review. Med. Sci. Sports Exerc. 15: 187-198.

Carpenter, M. B. and J. Sutin (1983) Human Neuroanatomy, p. 185, Williams and Wilkins, Baltimore.

Chevallier, A. (1979) Role of the somitic mesoderm in the development of the thorax in bird embryos. II. Origin of thoracic and appendicular musculature. J. Embryol. Exp. Morphol. 49: 73-88.

Chevallier, A., M. Kieny, and A. Mauger (1977) Limb-somite relationship: origin of the limb musculature. J. Embryol. Exp. Morphol. 41: 245-258.

Corliss, C. E. (1976) Patten's Human Embryology, p. 193, McGraw Hill, New York.
Carlson, B. M. and J. A. Faulkner (1983) The regeneration of skeletal muscle 
Duron, B. (1981) Intercostal and diaphragmatic muscle endings and afferents. In Regulation of Breathing, T. F. Hornbein, ed., Part 1, pp. 473-540, Marcel Dekker, Inc., New York

Gerding, R., N. Robbins, and J. Antosiak (1977) Efficiency of reinnervation of neonatal rat muscle by original and foreign nerves. Dev. Biol. 61: 177183.

Gillespie, M. J., T. Gordon, and P. H. Murphey (1983) Random reinnervation of LG and SOL muscles by their common nerve? Soc. Neurosci. Abstr. 9. 11 .

Gordon, T., N. Niven-Jenkins, and G. Vrbova (1980) Observations on neuromuscular connection between the vagus nerve and skeletal muscle. Neuroscience 5: 597-610.

Grinnell, A. D. and M. B. Rheuben (1979) The physiology, pharmacology, and trophic effectiveness of synapses formed by autonomic preganglionic nerves on frog skeletal muscle. J. Physiol. (Lond.) 289: 219-240.

Guth, L. and J. J. Bernstein (1961) Selectivity in the reestablishment of synapses in the superior cervical ganglion of the cat. Exp. Neurol. 4: 5969

Hansen-Smith, F. M. (1983) Development and innervation of soleplates in the freely grafted extensor digitorum longus (EDL) muscle in the rat. Anat Rec. 207: 55-67.

Hansen-Smith, F. M. and B. M. Carlson (1979) Cellular responses to free grafting of the extensor digitorum longus muscle of the rat. J. Neurol. Sci. 41: $149-173$.

Hoh, J. F. Y. (1975) Active and nonselective reinnervation of fast-twitch and slow-twitch rat skeletal muscle. J. Physiol. (Lond.) 251: 791-801.

Jirmanova, I. and S. Thesleff (1972) Ultrastructural study of experimenta muscle degeneration and regeneration in the adult rat. Z. Zellforsch. 131 77-97.

Karnovsky, M. J. (1964) The localization of cholinesterase activity in rat cardiac muscle by electron microscopy. J. Cell Biol. 23: 217-232.

Landmesser, L. (1971) Contractile and electrical responses of vagus innervated frog sartorius muscle. J. Physiol. (Lond.) 213: 707-725.

Landmesser, L. (1972) Pharmacological properties, cholinesterase activity and anatomy of nerve-muscie junctions in vagus-innervated frog sartorius. J. Physiol. (Lond.) 220: 243-256.

Langley, J. N. (1982) On the origin from the spinal cord of the cervical and upper thoracic sympathetic fibers, with some observations on white and gray rami communicantes. Philos. Trans. R. Soc. Lond. (Biol.) 183: 85124.

Langley, J. N. (1895) Note on regeneration of preganglionic fibers of the sympathetic. J. Physiol. (Lond.) 18: 280-284.

I angley, $\mathrm{J} . \mathrm{N}$. (1897) On the regeneration of preganglionic and of postganglionic visceral nerve fibers. J. Physiol. (Lond.) 22: 215-230.

Langley, J. N. and H. K. Anderson (1904) The union of different kinds of nerve fibers. J. Physiol. (Lond.) 31: 365-391.

Larnicol, N., D. Rose, D. Marlot, and B. Duron (1982) Spinal localization of the intercostal motoneurones innervating the upper thoracic spaces. Neurosci. Lett. 31: 13-18.

Lichtman, J. W. D. Purves, and J. W. Yip (1979) On the purpose of selective innervation of guinea pig superior cervical ganglion cells. J. Physiol. (Lond.)
292: $69-84$.

Liley, A. W. (1956) An investigation of spontaneous activity at the neuromus cular junction of the rat. J. Physiol. (Lond.) 132: 650-666.

Miledi, R. and E. Stefani (1969) Nonselective reinnervation of siow and fast muscle fibers in the rat. Nature 222: 569-571.

Murata, Y., H. Shibata, and T. Chiba (1982) A correlative quantitative study comparing the nerve fibers in the cervical sympathetic trunk and the locus of the somata from which they originate in the rat. J. Auton. Nerv. Syst. 6 : $323-333$

Njå, A. and D. Purves (1977a) Specific innervation of guinea pig superior cervical ganglion cells by preganglionic fibers arising from different levels of the spinal cord. J. Physiol. (Lond.) 264: 565-583.

Njå, A. and D. Purves (1977b) Reinnervation of guinea pig superior cervical ganglion cells by preganglionic fibers arising from different levels of the spinal cord. J. Physiol. (Lond.) 272: 633-651.

Ontell, M. D. Hughes, and D. Bourke (1982) Secondary myogenesis of normal muscle produces abnormal myotubes. Anat. Rec. 204: 199-207.

Purves, D., W. Thompson, and J. W. Yip (1981) Reinnervation of ganglia transplanted to the neck from different levels of the guinea pig sympathetic chain. J. Physiol. (Lond.) 313: 49-63.

Rando, T. A., C. W. Bowers, and R. E. Zigmond (1981) Localization of neurons in the rat spinal cord which project to the superior cervical ganglion. J. Comp. Neurol. 196: 73-83.

Redfern, P. A. (1970) Neuromuscular transmission in new-born rats. J. Physiol. (Lond.) 209: 701-709.

Riley, D. A. (1978) An investigation of selective reinnervation of rat skeletal muscles. Soc. Neurosci. Abstr. 4: 534

Rubin, E. and D. Purves (1980) Segmental organization of sympathetic preganglionic neurons in the mammalian spinal cord. J. Comp. Neurol. 192: $163-174$

Sanes, J. R., L. M. Marshall, and U. J. McMahan (1978) Reinnervation of muscle fiber basal lamina after removal of myofibers. Differentiation of regenerating axons at original synaptic sites. J. Cell Biol. 78: 176-198.

Smith, C. L. and Hollyday, M. (1983) The development and postnatal organization of motor nuclei in the rat thoracic spinal cord. J. Comp. Neurol. 220: 16-28.

Sperry, R. W. (1963) Chemoaffinity in the orderly growth of nerve fiber patterns and connections. Proc. Natl. Acad. Sci. U. S. A. 50: 703-709.

Weiss, P. and A. Hoag (1946) Competitive reinnervation of rat muscles by their own and foreign nerves. J. Neurophysiol. 9: 413-418.

Wigston, D. J. (1983) Innervation of individual guinea-pig superior cervical ganglion cells by axons with similar conduction velocities. J. Physiol. (Lond.) 334: 179-187

Wigston, D. J. and J. R. Sanes (1982) Selective reinnervation of adult mammalian muscles by axons from different segmental levels. Nature 299: $464-467$

Wigston, D. J. and J. R. Sanes (1983) A positional basis for selective reinnervation of adult rat muscles. Soc. Neurosci. Abstr. 9: 1059.

Wolpert, L. (1981) Positional information and pattern formation. Philos. Trans. R. Soc. Lond. (Biol.) 295: 441-450. 